\title{
URBOEKOLOGICAL SITUATION AND REGIONAL ANALYSIS OF POPULATION HEALTH IN UZBEKISTAN
}

\author{
a,bNilufar K. Komilova*,cNilufar N. Ermatova, aTura Rakhimova, bLolakhon K. Karshibaeva, \\ dMukhtor O. Hamroyev \\ ${ }^{a}$ National University of Uzbekistan named after Mirzo Ulugbek, Tashkent, Republic of Uzbekistan \\ ${ }^{b}$ Gulistan State University, Gulistan, Republic of Uzbekistan \\ 'State Testing Center under the Cabinet of Ministers of the Republic of Uzbekistan, Tashkent, Republic of Uzbekistan \\ dUrgench State University, Urgench, Republic of Uzbekistan.
}

\section{ART ICLE INF O}

\section{Article History}

Received: April 21, 2021

Revised: July 1, 2021

Accepted: July 30, 2021

\section{Keywords}

Urban ecology

Medical geography

Hypodynamics

Nosogeographic situation

Artificial environment

Noise

Man-made pressure

Diseases of development

Civilization

\section{A B S T R A C T}

Corresponding Author: Nilufar K. Komilova

Email: komilova-nk7173-1@unesp.co.uk

(c) The Author(s) 2021.

\section{INTRODUCTION}

As humanity enters the 21st century, it faces very complex, unresolved problems, including medical geography, which studies the causes and laws of environmental pollution, human ecology, nosocology, and the spread of related diseases on Earth. raises new issues. It should be noted that the rapid development of science and technology, the steady increase in human impact on nature and, consequently, a number of negative changes in the natural environment have a significant impact on human health (Dong et al., 2018; Xing and Ding, 2019). The acceleration of the urbanization process, in turn, is causing problems such as air, water and soil pollution. At the same time, cities are now becoming centers of noise that negatively affect the mental state of people. Noise is high today as a major 
source of damage to the nervous system, auditory organs, and heart, especially in large industrial and densely populated cities (Komilova, 2016). The development of urbanization, urbanization, huge agglomerations, conurbations and megacities, high concentration of production and the acceleration of other vital processes cause great inconvenience to people living in such an environment.

In highly urbanized areas, urbanism, as well as diseases of development or civilization, are more common and they are more directly related to the natural, ecological, economic, social aspects of these areas. Diseases of development or civilization are diseases that are common among the population of economically developed countries and are mainly specific to large cities (high noise, hypodynamics, severe air pollution, etc.). These include a number of diseases such as hypertension, ischemic heart disease, gastric and duodenal ulcers, diabetes, bronchial asthma, metabolic disorders, neuroses, mental disorders. Mortality and mortality rates in such areas are also relatively high (Komilova, 2021; Ventriglio et al., 2020).

It should be noted that the desire to live in cities, the way of life there is attracting more and more people's attention. By 2020, 56 percent of the world's population will live in cities, and that number is growing. Today, the urban environment is gaining complex - natural, natural-anthropogenic, socio-economic features that have an increasingly strong impact on people. The human lifestyle in an urban environment is influenced by the living environment in the home, the artificial environment (manufacturing plants, various buildings, transport and roads, etc.), different cultural landscapes (parks and alleys), socio-economic and sociopsychological environment (Flies et al., 2020). Improving the ecological environment of the city, first of all, to raise the level of culture of the urban population, to create a high-quality ecological infrastructure in and around the city in order to use a quality living environment, to create an urban architectural landscape in accordance with environmental requirements, energy, industry, transport, water consumption, achieving compliance with environmental requirements of industrial wastes, etc., depends in many respects on the explanation of environmental norms in the urban environment to the population (Parris, 2018; Thomson and Newman, 2021). In other words, urban ecology is a field of integrated measures related to the preservation, restoration and creation of a scientifically based quality, ecologically clean urban living environment in urban areas (regions, states, provinces, cities or regions) in order to protect nature (Komilova et al., 2020).

\section{MATERIALS AND METHODS}

Under the influence of various ecological, negative anthropogenic factors of the Republic, the number of negative environmental factors affecting the medical geographical situation, the environment, the human body is increasing. It plays an important role in ensuring sustainable development, i.e. the health of the next generation. The health of mothers is extremely important in the health of the next generation. For this reason, we have developed a system of factors that affect maternal and child health. It consists of: personality activity, environmental factors, attitudes of family and others, social environment, etc.

At the same time, it should be noted that there are still unresolved issues in improving the health of the population in our country. For example, today in the country, maternal and infant mortality, some disease groups (respiratory, malignant tumors, nervous system, etc.) are declining, but among the population there are blood and blood-forming organs, heart, stroke, accidents and poisonings, groups of diseases related to the digestive system are increasing. Analysis and study of regional aspects of these problems is one of the main tasks of medical geography (Komilova et al., 2020). In medical geographical research, the analysis of regions in terms of nosogeographic situation is of great importance. It is known that environmental factors can include fresh air, clean water, environmentally friendly food, education, physical activity, drinking, smoking, etc. should not be less than a year. The influence of family members, neighbors and neighbors also plays an important role in maternal and child health (Cox et al., 2018).

Historical data show that the first cities appeared on our planet 5,000 years ago. Ancient cities began to appear mainly in the valleys, on the banks of the Nile, Tigris, Euphrates, Hindu, Huanghe rivers, in places suitable for agriculture and animal husbandry. The improvement of living conditions in these settlements, the possibility of constant communication between people further intensified the development of the ancient cities. Thus, by the beginning of the century, the population was 1 million. Rome, Athens, Sparta, and other city-states 
began to appear. These cities gave humanity the first results of civilization: achievements in public administration, architecture, culture, art, military skills (Tellier, 2019).

\section{RESULTS AND DISCUSSION}

The past 20 years, the environmental problems of the urban environment have become more acute. The causes of environmental problems in the urban environment include the expansion of urban areas, the growth of agglomerations, the emergence of large urban areas, the increase in population density in many countries around the world. The above cases, in turn, lead to unemployment, which leads to an increase in crime, deterioration of sanitation and an increase in morbidity rates in the population.

In the early stages of the urban formation process, the townspeople used local water and food sources, horses and other domestic animals, and mostly manual labor was used in production. Waste emissions into the environment were mainly waste generated during human life and from domestic animals. Among the environmental problems of ancient cities are the pollution of water from these wastes and the resulting infectious diseases. The next stage of urbanization coincides with the development of land and water transport, the emergence of roads, the use of thermal energy for transport and production purposes. Especially in the sixteenth century, cities and their populations began to grow rapidly. However, at this stage, it can be said that the level of pollution of the city with industrial waste has not yet exceeded the norm. The third phase of urbanization dates back to the 19th century, and this process is associated with the Industrial Revolution, which had a major impact on the environment. By 1900, Britain was literally the first urbanized country, and by the second half of the twentieth century, all industrialized countries had become urbanized.

By 1800 , the urban population was $3 \%$ of the world's population, by 1900 it was $13.6 \%$, by the end of the 20th century and the first quarter of the 21st century, the world's population exceeded 7 billion, and by 2020 more than half (56\%) of the world's population lives in cities (Komilova, 2021). Today, the acceleration of the urbanization process, in turn, has been recognized by scientists as a serious threat to human health. The urban environment - especially the human nervous system, has an impact on the general condition of the body. It is advisable to pay attention to a number of factors:

1. Noise is one of the main sources of public health in urban areas, especially road transport. The noise level on the main streets of cities reaches $95 \mathrm{~dB}$. Noise from trams and subway trains does not have a serious negative impact on our body.

2. It should be noted that noise - causes changes in the functional state of the central nervous and cardiovascular systems. Ischemic heart disease, hypertension, and elevated blood cholesterol are common in people living in noisy areas. Exposure to noise can affect the central nervous system, leading to sleep disturbances, chronic fatigue, headaches, decreased work activity and resistance to disease. However, there are also low-frequency vibrations that are inaudible to the human ear (we can include wind, lightning, sea and ocean waves, etc.) and some anthropogenic sources (transformers, power lines, etc.) can also be added to them. The frequency oscillations of such devices are assumed to correspond to the alpha rhythm, and under their influence the symptoms characteristic of seasickness appear in the upper nervous system. Constant fatigue can lead to decreased vision and even death.

3. Exhaust gases from industrial enterprises, toxic compounds lead to air and water pollution. This leads to respiratory diseases, allergies and oncological diseases. In economically developed, urbanized countries, cancerrelated deaths are leading the way. A number of studies have been conducted by scientists on the relationship between cancer and the ecological situation, i.e. the relationship between the environment, including the ecological condition of the city and the incidence of malignant neoplasms of the population. Allergic diseases, which occur under the influence of pollutants previously unknown to the human environment in the urban environment, also cause pathological conditions. At the same time, the analysis of the dynamics of the amount of pollutants emitted into the atmosphere in Uzbekistan in recent years shows that the indicators have grown over the years, especially in Tashkent region and the city Komilova (2010); Komilova (2021) (Table 1).

Table 1. Atmospheric pollutants (thousand tons). 


\begin{tabular}{lcccc}
\hline & \multicolumn{3}{c}{ Year } \\
\cline { 2 - 5 } & 2010 & 2011 & 2018 & 2019 \\
\hline Republic of Uzbekistan & 729.0 & 788.2 & 883.7 & 952.8 \\
The Republic of Karakalpakstan & 29.2 & 23.5 & 34.0 & 37.2 \\
\hline \multicolumn{1}{c}{ Regions } & & & \\
\hline Andijon & 8.7 & 13.6 & 15.9 & 14.3 \\
Bukhara & 75.5 & 71.7 & 74.8 & 69.1 \\
Jizzakh & 23.8 & 17.3 & 11.8 & 4.3 \\
Kashkadarya & 141.2 & 142.5 & 152.2 & 140.4 \\
Navoi & 40.3 & 45.2 & 49.9 & 43.6 \\
Namangan & 5.4 & 5.6 & 15.2 & 15.8 \\
Samarkand & 51.5 & 51.8 & 52.1 & 44.2 \\
Surxandaryo & 3.5 & 3.3 & 5.1 & 6.9 \\
Sirdaryo & 21.0 & 58.7 & 60.5 & 47.8 \\
Tashkent & 257.6 & 280.3 & 336.6 & 397.9 \\
Fergana & 43.0 & 42.8 & 53.2 & 49.6 \\
Khorezm & 4.8 & 4.9 & 7.1 & 7.2 \\
Tashkent & 23.5 & 27.0 & 15.3 & 74.5 \\
\hline
\end{tabular}

In areas with high levels of urbanization, the psyche of people is also greatly affected by rhythmic signals from conveyor lines, machines and other devices that work in a rhythmic, smooth-moving mechanisms - factories and plants. The appearance of the urban environment, i.e. the architectural environment, also has an effect on the human nervous system (especially its uniformity: modern multi-storey buildings, its flat windows, etc.). Close-up vision is several times more common in urban areas than in rural areas. Constantly looking at the same objects causes pathological conditions related to the visual system.

It is known that colors have a serious impact on a person's mental state. Bright colors have a positive effect on the human psyche. People living in the city are exposed to a lot of gray, brown and other colors every day, and this condition causes many mental illnesses (Denisov et al., 2008; Robertson, 2019). The air in cities smells of gasoline, exhaust fumes, paint, asphalt, and they often cause allergic reactions (such cases can also be observed due to perfumes, cosmetics, washing powder). The predominance of a particular odor is directly related to the urban industry or the specialized industries of a particular area. Almost every city has its own unique smell, through which we can learn about the industry (metallurgy, chemistry, textiles, food, etc.) that dominates for its economy. These substances released into the air affect not only the sense of smell and the nervous system, but also our other organs. Another aspect of modern big city life is characterized by the formation and accumulation of large amounts of solid, liquid and gaseous wastes of industrial and domestic origin. Liquid waste seeps into the ground and contaminates drinking water sources and groundwater. Solid waste also has a significant impact on the nosoecological situation in cities. The data show that the majority of household waste is also collected around cities and towns of the country (the main part of solid waste is paper and food waste, plastic and synthetic materials, burning them in landfills releases many toxic substances (dioxin, fluorine compounds, etc.) into the atmosphere. causes the output)). Household waste pollutes the natural environment, increasing epidemiological and toxicological risks. Rodents and other animals accumulate in large numbers in landfills and play an important role in the spread of many infectious diseases. In large cities, the quality of drinking water and sanitation also play an important role. Regular use of contaminated water leads to a sharp decline in immunity, the development of a number of diseases in humans (Baranovskaya et al., 2013). Hypodynamics in urban areas, ie low mobility, is also much higher than in rural areas. Low physical activity, poor nutrition, metabolic disorders lead to an increase in the number of overweight people, the development of cardiovascular diseases, including arterial hypertension, myocardial infarction, stroke, as well as diabetes. The urban environment has a significant impact on human lifestyle. Man creates for himself a number of complex urban systems, strives for better, more comfortable living - to improve living conditions, creates a new artificial environment that increases the well-being of 
life. Unfortunately, all of this separates him from the natural environment in which he actually belongs, and it is too late to realize that increasingly complex healthrelated situations are occurring.

\section{CONCLUSIONS}

The solution of environmental problems in urbanized areas is largely determined by the socio-demographic and environmental policy on a scientific basis. The ethnic identity, lifestyle and traditions of the population of our country play an important role in this. In general, each region has its own environmental problems related to public health. Solving these problems, encouraging the population to think ecologically sound is beneficial for their health, educating the younger generation to be spiritually and physically healthy. After all, only in an ecologically clean and healthy environment it is possible to bring up a comprehensively developed generation. It should be noted that in order to reduce the negative impact of the environment on human health, it is necessary to:

1. For a healthy environment, pollutants in the air should not exceed the allowable amount.

2. Use of trees, bushes and lawns in the formation of a sanitary zone $(10000,500,300$ meters) around industrial enterprises.

3. Transition to safe modes of transport.

4. Wastewater is treated in various ways and added to water bodies.

5. Training of highly spiritual and ecologically cultured personnel - improvement of the ecological condition of the environment while protecting nature.

In the protection of nature, it is necessary to pay attention to its aspects (health, economic, cultural, educational, aesthetic) among the general public, to carry out advocacy work.

\section{REFERENCES}

Baranovskaya, N. V., T. V. Usmanova and I. A. Matveyenko. 2013. Modern problems of ecology and nature management. Tomsk Polytechnic University Press, Tomsk.

Cox, D. T. C., D. F. Shanahan, H. L. Hudson, R. A. Fuller and K. J. Gaston. 2018. The impact of urbanisation on nature dose and the implications for human health. Landscape and Urban Planning, 179: 7280.

Dong, R., S. Li, Y. Zhang, N. Zhang, T. Wang, X. Tan and X. $\mathrm{Fu}$. 2018. Analysis of urban environmental problems based on big data from the urban municipal supervision and management information system. Ecological Indicators, 94: 5269.

Flies, E. J., L. J. Clarke, B. W. Brook and P. Jones. 2020. Urbanisation reduces the abundance and diversity of airborne microbes - but what does that mean for our health? A systematic review. Science of The Total Environment, 738: 140337.

Komilova, N. 2010. Territorial Analysis of Medicalgeographycal Conditions and the Problems of Health of the Population of the Republic of Uzbekistan. Journal of Environmental Science and Engineering, 4.

Komilova, N. K. 2016. Theoretical and practical issues of medical geography. Şarq, Tashkent.

Komilova, N. K. 2021. Territorial analysis of medical geographical conditions of Uzbekistan. Current Research in Behavioral Sciences, 2: 100022.

Komilova, N. K., A. K. Ravshanov, L. K. Karshibaeva, K. Q. Ishankulova and Z. N. Madrahimova. 2020. Some Theoretical and Practical Issues of Medical Geographical Research. Indian Journal of Forensic Medicine \& Toxicology.

Parris, K. M. 2018. Existing ecological theory applies to urban environments. Landscape and Ecological Engineering, 14: 201-208.

Tellier, L.-N. 2019. Urban World History. Springer International Publishing.

Thomson, G. and P. Newman. 2021. Green Infrastructure and Biophilic Urbanism as Tools for Integrating Resource Efficient and Ecological Cities. Urban Planning, 6: 75-88.

Ventriglio, A., J. Torales, J. M. Castaldelli-Maia, D. De Berardis and D. Bhugra. 2020. Urbanization and emerging mental health issues. CNS Spectrums, 26: 43-50.

Xing, C. and Y. Ding. 2019. Research on Urban Ecoenvironmental Problems and Sustainable Development. IOP Conference Series: Earth and Environmental Science, 300: 032103. 
Publisher's note: EScience Press remains neutral with regard to jurisdictional claims in published maps and institutional affiliations.

(c)

Open Access This article is licensed under a Creative Commons Attribution 4.0 International License, which permits use, sharing, adaptation, distribution and reproduction in any medium or format, as long as you give appropriate credit to the original author(s) and the source, provide a link to the Creative Commons license and indicate if changes were made. The images or other third-party material in this article are included in the article's Creative Commons license, unless indicated otherwise in a credit line to the material. If material is not included in the article's Creative Commons license and your intended use is not permitted by statutory regulation or exceeds the permitted use, you will need to obtain permission directly from the copyright holder. To view a copy of this license, visit http://creativecommons.org/licenses/by/4.0/. 